\title{
ECO $_{2}$ EFICIÊNCIA EM Frotas De CARGa
}

\author{
Décio Magioli Maia ${ }^{1}$, Rogério Nascimento de Carvalho ${ }^{1}$ \\ ${ }^{1}$ PETROBRAS
}

E-mails: deciomaia@petrobras.com.br, rogerio.carvalho@petrobras.com.br

\section{RESUMO}

Atualmente a procura por aumento da eficiência energética dos motores e veículos é crescente, não só pela redução do consumo dos recursos naturais mas também pela redução dos gastos com a energia. Aliado a isto, aumenta cada vez mais a consciência ambiental de que podemos minimizar e até reverter os efeitos nocivos dos poluentes que lançamos na atmosfera, onde a emissão de $\mathrm{CO}_{2}$ tem destaque nas discussões mundiais.

Quando as atenções se concentram nos veículos leves de passageiros e de pequena carga, o país já conta com o Programa Brasileiro de Etiquetagem Veicular - PBEV, que possibilita a escolha do veículo ou frota a ser adquirida pela sua eficiência energética, que resultará num menor consumo do combustível a ser utilizado e uma correspondente menor emissão de $\mathrm{CO}_{2}$. Este trabalho aborda de forma quantitativa este potencial ganho, ilustrando a redução de consumo e de $\mathrm{CO}_{2}$ por ano de utilização de uma frota real de 1.000 veículos leves.

Quanto aos veículos pesados de transporte de carga, poucos trabalhos no Brasil apresentam soluções possíveis de serem implantadas a curto e médio prazos e, mesmo assim, com resultados apenas qualitativos. Este trabalho selecionou uma frota real de 9.000 caminhões de transporte de carga e, partindo de soluções mais convencionais até aquelas mais disruptivas, estimou os benefícios de redução do consumo de óleo diesel e da respectiva emissão de $\mathrm{CO}_{2}$ durante um ano de utilização empregando algumas sugestões, chegando a números surpreendentes.

\section{INTRODUÇÃO}

Diante da crescente preocupação da humanidade com o uso racional de energia e com a preservação do meio ambiente, inúmeras ações têm sido implementadas ao redor do mundo, no sentido de se desenvolver máquinas e equipamentos que aliem uma maior eficiência com a redução de emissões de substâncias poluentes ou causadoras de danos globais ao meio ambiente. Normalmente, essas ações são impulsionadas por iniciativas compulsórias para atendimento a legislações ou de fomento a partir de incentivos fiscais ou de conscientização dos consumidores.

Esse movimento é claramente percebido na história da indústria da mobilidade, na qual novas tecnologias são continuamente desenvolvidas e implementadas para o atendimento aos requisitos de qualidade e desempenho, cada vez mais exigentes, dos consumidores e das regulamentações obrigatórias. 
Na busca da utilização mais eficiente dos veículos, com menor consumo de combustível e emissão de $\mathrm{CO}_{2}$, uma série de alternativas tecnológicas tem se apresentado e afetam a todos os principais componentes do veículo, como por exemplo, a redução de peso com a aplicação de materiais mais leves, o uso de "pneus verdes" e ajustes aerodinâmicos.

Uma série de novas tecnologias de propulsão de veículos tem sido vastamente estudadas e implementadas com ganhos de eficiência muito significativos, como: a utilização de motores menores e mais leves, comumente chamada de "downsizing"; novos sistemas de injeção de combustível, como a injeção direta de gasolina; o uso de turbo-compressores; novas tecnologias de comando otimizado de válvulas de admissão; variação da taxa de compressão; desativação de cilindros. A introdução de motorização elétrica também tem ganhado força nos últimos anos, associada ou não a motores a combustão interna.

Os primeiros programas de etiquetagem veicular no mundo surgiram na década de 1970 e atualmente vários países utilizam essa ferramenta para fomentar a produção de veículos mais eficientes. No Brasil, já na década de 1980, se iniciou a disponibilização das informações de consumo de combustível, que perdeu força anos depois. Porém, em 2009, foi lançado o Programa Brasileiro de Etiquetagem Veicular (PBEV), que está atualmente na sua sétima edição e já conta com uma quantidade significativa de fabricantes e modelos. Entretanto, para os veículos pesados de carga, ainda não há um programa semelhante.

Este trabalho apresenta alternativas possíveis de renovação eficiente de frotas compostas por veículos leves e pesados, aplicando as informações disponíveis de eficiência energética dos veículos ou introduzindo novos componentes e tecnologias que mitiguem o consumo de combustível. Para tanto é avaliada uma frota real de 9.000 caminhões de transporte de carga e 1.000 veículos leves, obtendo-se resultados potenciais bastante significativos.

\section{FROTA DE VEÍCULOS LEVES}

Geralmente a frota de veículos leves de apoio de uma empresa de transporte de carga é constituída de modelos compactos, como no caso da empresa selecionada para este trabalho. Adotou-se, então, esta categoria de veículos para se verificar qual o potencial de redução do consumo e da emissão de $\mathrm{CO}_{2}$ já que, uma possibilidade seria, numa renovação desta frota, substituir o modelo do veículo atual pelo mais eficiente desta categoria.

No Brasil existe, desde 2009, o Programa Brasileiro de Etiquetagem Veicular (PBEV), que é coordenado pelo Instituto Nacional de Metrologia, Normalização e Qualidade Industrial (INMETRO) em parceria com o Programa Nacional de Racionalização do Uso dos Derivados do Petróleo e do Gás Natural (CONPET), administrado pela Petrobras.

O PBEV visa disponibilizar aos consumidores as informações de eficiência energética que lhes possibilitem avaliar este parâmetro no momento da compra de um novo veículo. Para tanto, o programa tem como principal ferramenta a Etiqueta Nacional de Conservação de Energia (ENCE), aposta nos produtos nos pontos de venda, além de informações disponibilizadas na Internet [1,2] e em um aplicativo para smartphones.

Os valores de consumo são declarados pelas empresas participantes do programa e são obtidos seguindo a metodologia definida pela Norma ABNT 7024[3], na qual o veículo é ensaiado sobre um dinamômetro de chassis calibrado com informações levantadas em pista a partir do procedimento de desaceleração livre, segundo a norma ABNT 10312[4]. 
São obtidos os valores das autonomias urbana e em estrada, em $\mathrm{km} / \mathrm{L}$, calculados a partir das emissões dos gases hidrocarbonetos totais (THC), monóxido de carbono (CO) e dióxido de carbono $\left(\mathrm{CO}_{2}\right)$, e das frações percentuais de gasolina e etanol no combustível de teste, a partir do Método do Balanço de Carbono. A combinação ponderada destes valores resulta na autonomia combinada do veículo.

Como os veículos leves atualmente no Brasil são movidos por misturas de gasolina com etanol anidro e/ou por etanol hidratado (EHC), na metodologia do PBEV é calculado o consumo energético, em $\mathrm{MJ} / \mathrm{km}$, para possibilitar a comparação entre os modelos, independentemente do combustível de teste. O consumo energético é calculado pela razão entre a densidade energética do combustível, em $\mathrm{MJ} / \mathrm{L}$ e a autonomia combinada, em $\mathrm{km} / \mathrm{L}$. Os valores padronizados para a densidade energética dos combustíveis estão listados na tabela 1 e o procedimento completo do PBEV [5] é ilustrado na figura 1.

Tabela 1 - Densidade Energética dos Combustíveis para o Ciclo Otto

\begin{tabular}{|c|c|c|c|c|}
\hline Propriedade & Unidade & $\boldsymbol{E 0 0}$ & $\boldsymbol{E 2 2}$ & $\boldsymbol{E H R}$ \\
\hline Poder Calorífico & $\mathrm{MJ} / \mathrm{kg}$ & 43,06 & 38,92 & 24,80 \\
\hline Densidade & $\mathrm{kg} / \mathrm{L}$ & 0,735 & 0,745 & 0,810 \\
\hline Densidade Energética & $\mathrm{MJ} / \mathrm{L}$ & 31,65 & 28,99 & 20,09 \\
\hline
\end{tabular}

E00 - gasolina padrão sem adição de etanol hidratado.

E22 - mistura de $78 \%$ de gasolina padrão e $22 \%$ de etanol hidratado.

EHR - etanol hidratado de referência.

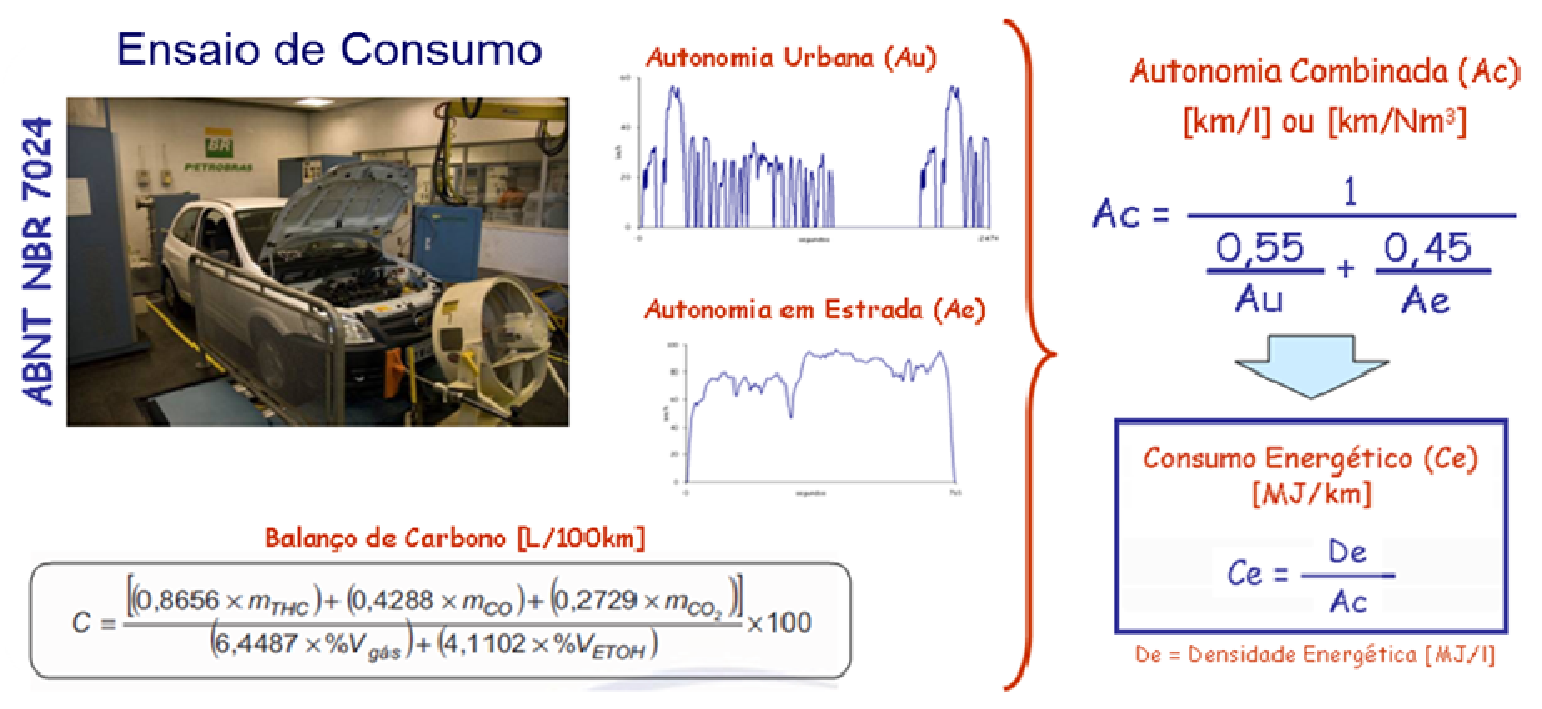

Figura 1. Medição do Consumo Energético de Veículos Leves

A partir do resultado obtido do consumo energético para cada veículo de uma mesma categoria, definida pelo tamanho e/ou pela aplicação dos veículos, é possível, através de um tratamento estatístico, estabelecer a dispersão entre eles.

Os veículos cujos consumos energéticos ficam no entorno da mediana são classificados com a letra C. Aqueles com consumos piores são classificados com as letras D e E e os melhores com as letras B e A, como exemplificado na figura 2. Da mesma forma, a classificação geral de todos os veículos participantes do programa também é determinada, utilizando-se as letras de A a E. 


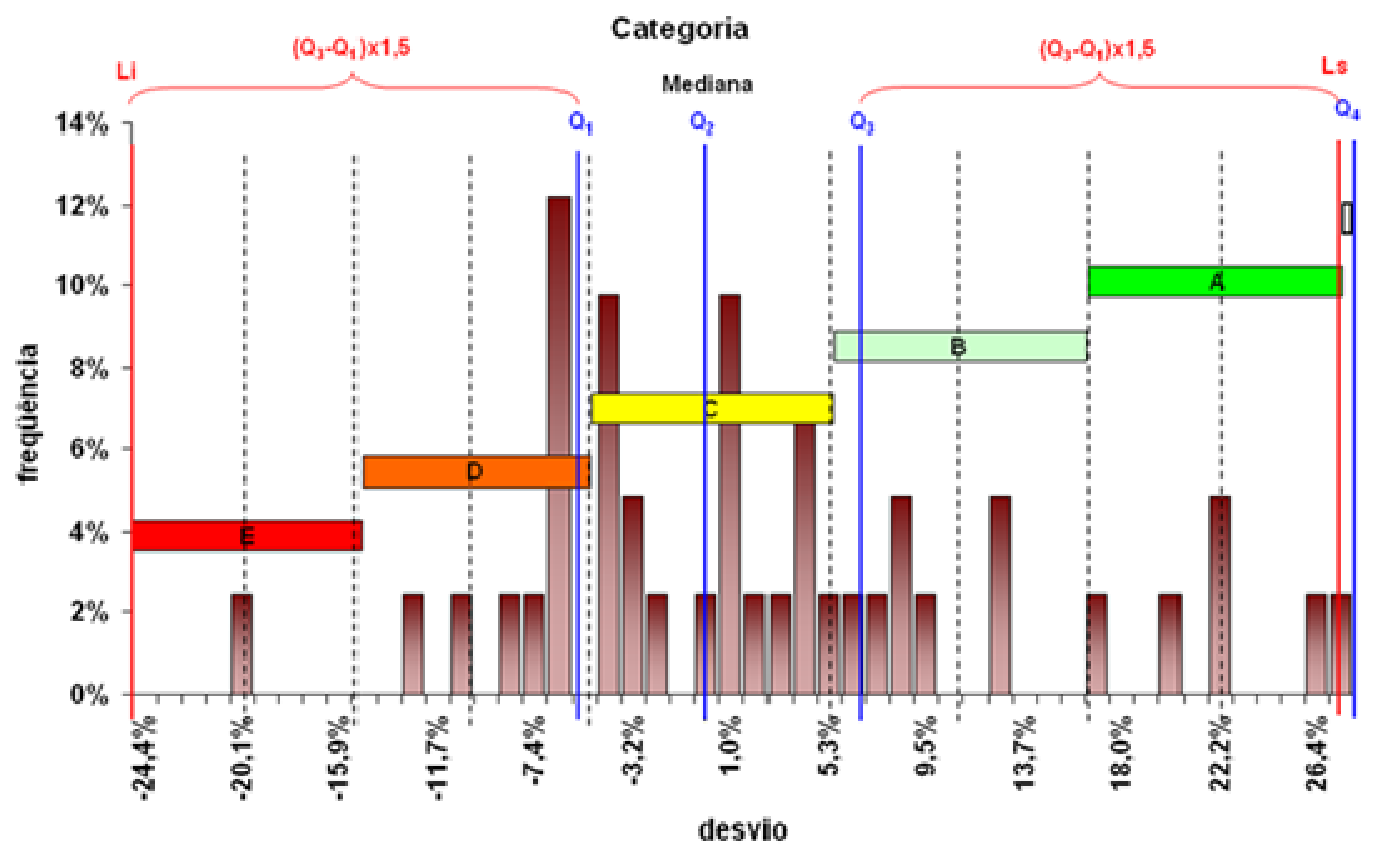

Figura 2. Metodologia Estatística de Classificação

Finalmente, os veículos assim classificados são apresentados numa tabela através dos sites do Inmetro [1] e do Conpet [2] e pela etiqueta (ENCE) afixada num dos vidros, com a letra da sua respectiva classificação na categoria, além de informações das autonomias urbana e em estrada para cada combustível utilizado no caso dos veículos flexfuel. Também são disponibilizadas informações das emissões de $\mathrm{CO}_{2}$, conforme mostrado na Figura 3.

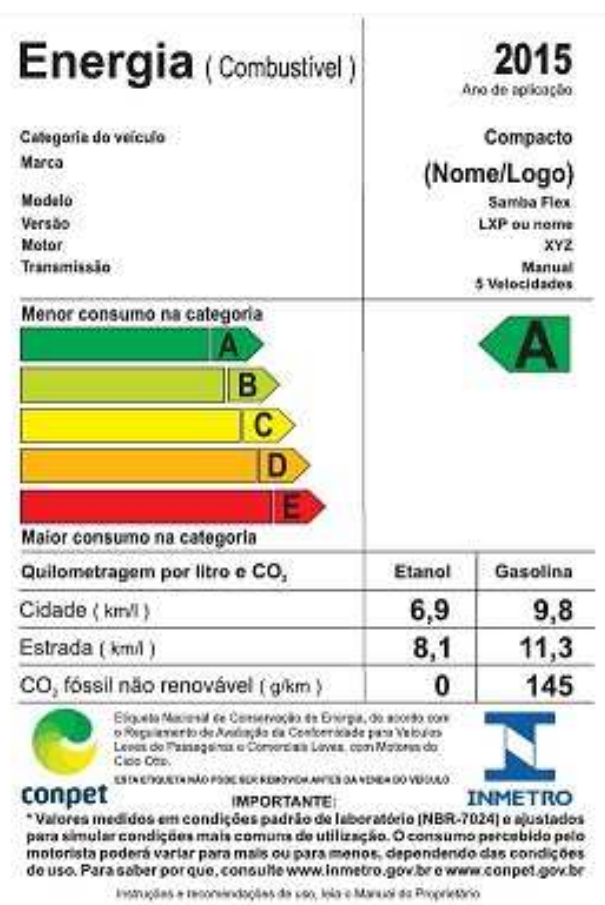

Figura 3. Etiqueta do PBEV

Adicionalmente, veículos com a classificação A ou B na sua categoria e A ou B na categoria geral, que abrange todos os veículos inseridos no programa, recebem o Selo CONPET, distinção maior no Brasil para o baixo consumo energético.

Considerando-se então os dados publicados no PBEV do ano de 2015, para a frota selecionada de 1.000 veículos leves, compactos, cada um rodando cerca de $20.000 \mathrm{~km} / \mathrm{ano}$, a primeira alternativa é sugerida: 


\subsection{Primeira alternativa: Selecionar a renovação da frota "leve" pelo PBEV:}

Conforme os dados publicados pelo PBEV em 2015, o melhor veículo em relação ao consumo combinado de gasolina na categoria compacto (A-categoria e A-geral) percorre $13,9 \mathrm{~km} / \mathrm{l}$ e o atualmente utilizado na frota avaliada (C-categoria e B-geral) apenas $11,2 \mathrm{~km} / \mathrm{l}$. Rodando cerca de $20.000 \mathrm{~km} / \mathrm{ano}$, o primeiro consome um total de 1.439 1/ano de gasolina, enquanto o segundo 1.786 l/ano.

A diferença, portanto, entre estes veículos é de 347 litros de gasolina por ano, podendo totalizar uma economia de até 347.0001 de gasolina por ano de rodagem da frota, correspondendo a 19,3\% do consumo anual de 1,8 Milhões de litros.

A respectiva diferença de emissão de $\mathrm{CO}_{2}$ fóssil entre eles seria de $460 \mathrm{~kg}$ por ano para cada veículo, com potencial redução de até 460 toneladas de $\mathrm{CO}_{2}$ fóssil por ano para toda a frota.

\section{FROTA DE VEÍCULOS PESADOS DE CARGA}

A metodologia atualmente aplicada no Brasil para medição das emissões de poluentes e do consumo de combustível dos veículos pesados é realizada com o motor instalado num banco de provas, que não encontra correlação direta com a utilização no campo, impossibilitando uma classificação dos veículos que utilizam estes motores.

Atualmente no Brasil ainda não existe uma classificação dos veículos pesados quanto ao consumo de combustível, impossibilitando a seleção dos mesmos de forma semelhante aos veículos leves.

Sendo assim, as seguintes alternativas são sugeridas para a seleção de veículos mais eficientes para uma frota de veículos pesados de carga.

\subsection{Segunda alternativa: Seleção por fase do PROCONVE}

Procurou-se, então, analisar o consumo de combustível das diferentes fases do PROCONVE (Programa de Controle de Poluição do Ar por Veículos Automotores), estabelecido pelo IBAMA (Instituto Brasileiro do Meio Ambiente e dos Recursos Naturais Renováveis), em função da significativa redução das emissões de poluentes destas fases, conforme mostrado na figura 4 . 

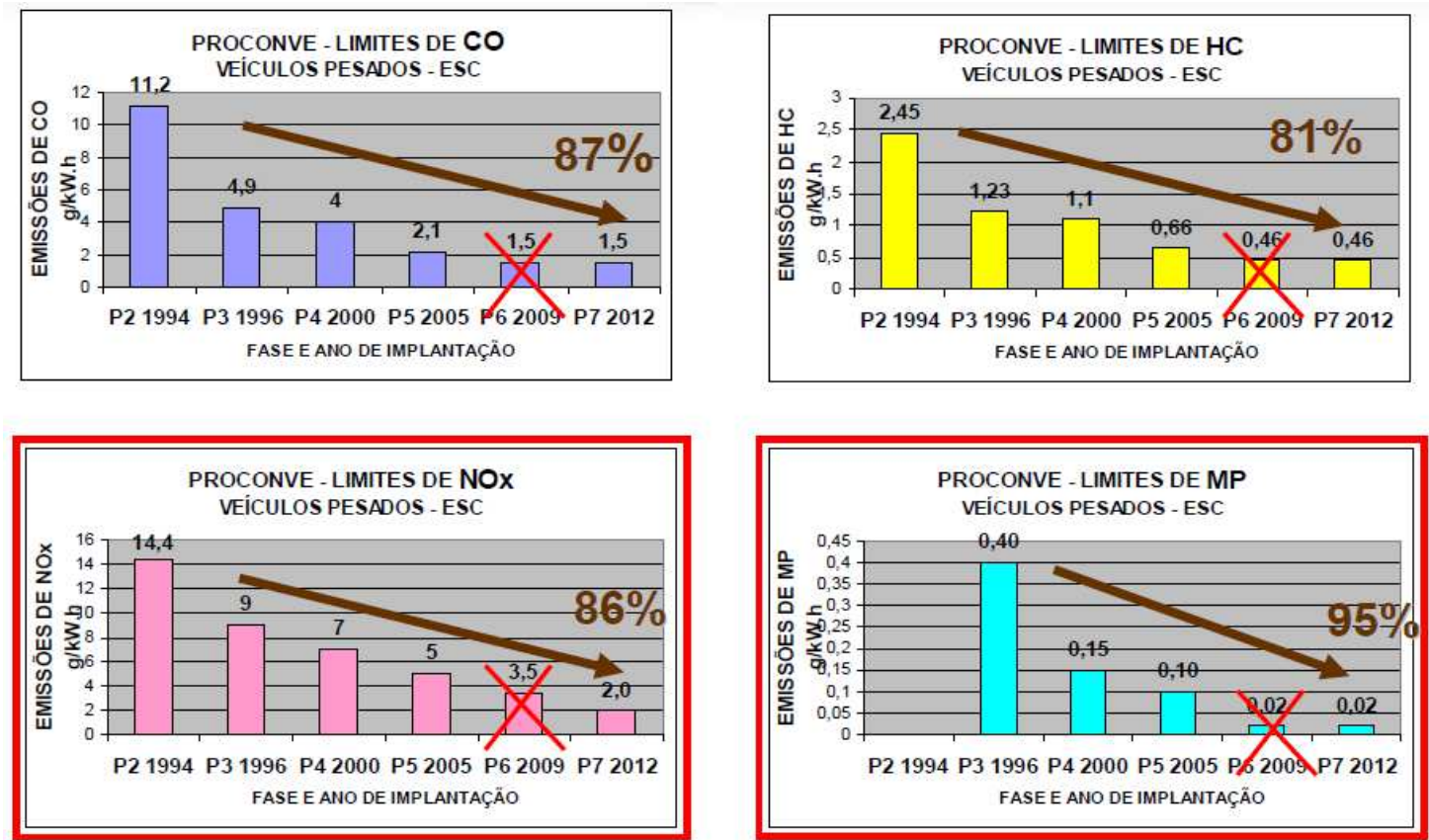

Figura 4. Redução das emissões com PROCONVE

Baseando-se no $2^{\underline{0}}$ Inventário Nacional de Emissões Atmosféricas por Veículos Automotores Rodoviários de 2013 [6], o mais atual do país, pode-se verificar o perfil do consumo de combustível por fase do PROCONVE, como mostrado na Tabela 2.

Tabela 2 - Consumo específico de combustível de motores Diesel por fase do PROCONVE

\begin{tabular}{|c|c|c|c|c|}
\hline Ano/modelo & Fase PROCONVE & \multicolumn{2}{|c|}{ Categorias } & $\mathbf{g}_{\text {diesel }} / \mathbf{k W h}$ \\
\hline- & Pré-PROCONVE, P1 e P2 & \multicolumn{2}{|c|}{-} & 225 \\
\hline- & P3 & \multicolumn{2}{|c|}{-} & 218 \\
\hline- & $\mathrm{P} 4$ & \multicolumn{2}{|c|}{-} & 210 \\
\hline 2004-2010 & P5 & \multicolumn{2}{|c|}{-} & 220 \\
\hline \multirow{9}{*}{2011} & \multirow{9}{*}{ P5 } & \multirow{5}{*}{ Caminhões } & Semileves & 238 \\
\hline & & & Leves & 212 \\
\hline & & & Médios & 231 \\
\hline & & & Semipesados & 228 \\
\hline & & & Pesados & 234 \\
\hline & & \multirow{3}{*}{ Ônibus } & Urbanos & 225 \\
\hline & & & Micro-ônibus & 225 \\
\hline & & & Rodoviários & 214 \\
\hline & & \multicolumn{2}{|l|}{ Comercias Leves } & 241 \\
\hline \multirow{8}{*}{2012} & \multirow{8}{*}{ P7 } & \multirow{5}{*}{ Caminhões } & Semileves & 243 \\
\hline & & & Leves & 226 \\
\hline & & & Médios & 225 \\
\hline & & & Semipesados & 219 \\
\hline & & & Pesados & 208 \\
\hline & & \multirow{3}{*}{ Ônibus } & Urbanos & 224 \\
\hline & & & Micro-ônibus & 224 \\
\hline & & & Rodoviários & 216 \\
\hline
\end{tabular}

Como a frota selecionada possui 9.000 veículos pesados, sendo cerca de $38 \%$ deles com tecnologia P5, composta por cerca de 1.600 semipesados e 1.800 pesados, cada um deles com rodagem anual de aproximadamente $54.000 \mathrm{~km}$, sugere-se a segunda alternativa:

Utilizando os valores de consumo do Inventário de Emissões, passando todos os caminhões da tecnologia P5 para a P7, os semipesados passariam do consumo médio de 228 para $219 \mathrm{~g} / \mathrm{kWh}$ e os pesados de 234 para $208 \mathrm{~g} / \mathrm{kWh}$, o que traria uma economia de diesel de cerca de 5 milhões de litros por ano, que correspondem a $3 \%$ do consumo de toda a frota (170 MM 1). Complementando, evita-se a emissão de 13,3 mil toneladas de $\mathrm{CO}_{2}$ por ano. 
2.2. Terceira alternativa: Adoção de tecnologias embarcadas

Adicionalmente à seleção do motor pela fase do PROCONVE, é possível introduzir diversas tecnologias de componentes, já consagradas no exterior [7], mas ainda não utilizadas em larga escala no Brasil, como pode ser visto na Figura 5.

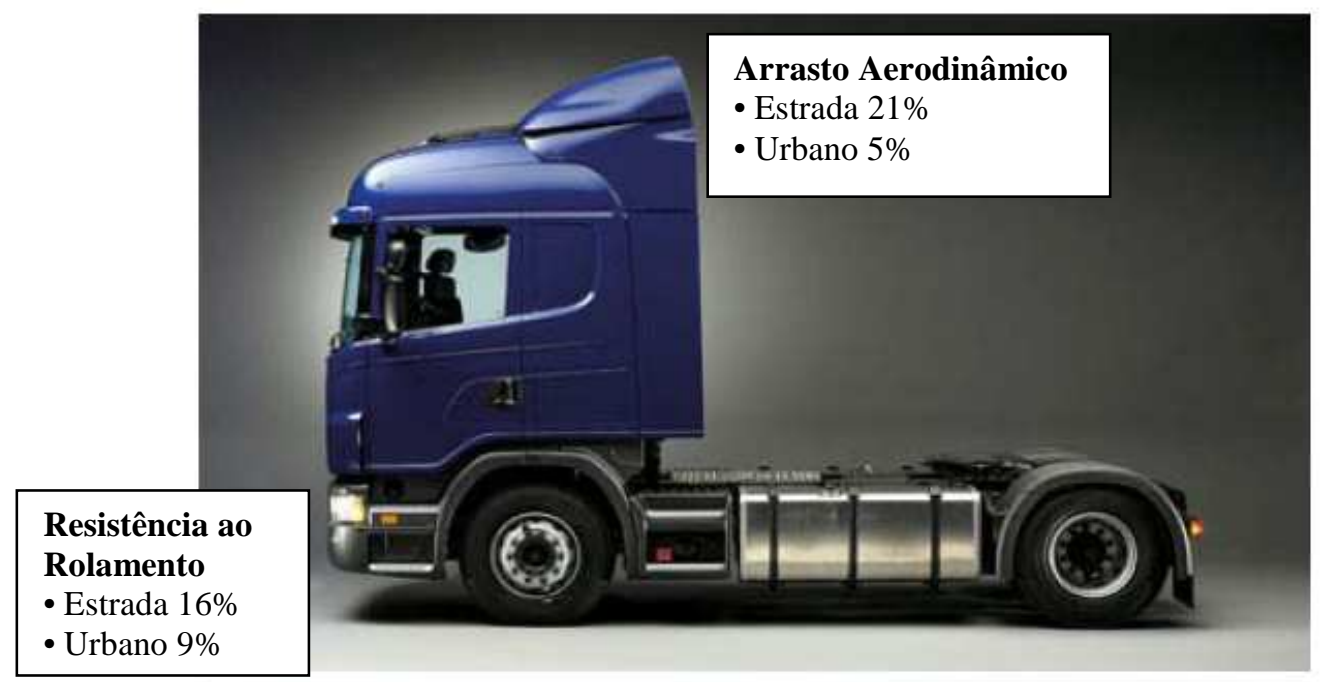

Figura 5. Exemplos de oportunidades para melhoria na eficiência veicular (Balanço de Energia)

Como exemplos de redução da resistência à rolagem, pode-se citar as tecnologias dos pneus, incorporando sílica à borracha normalmente utilizada, a substituição da base de duas rodas por uma roda mais larga e com o pneu correspondente e o já consagrado sistema de monitoração e enchimento embarcado dos pneus.

A Figura 6 apresenta as tecnologias embarcadas já certificadas nos EUA, com os respectivos ganhos de eficiência energética e custos.

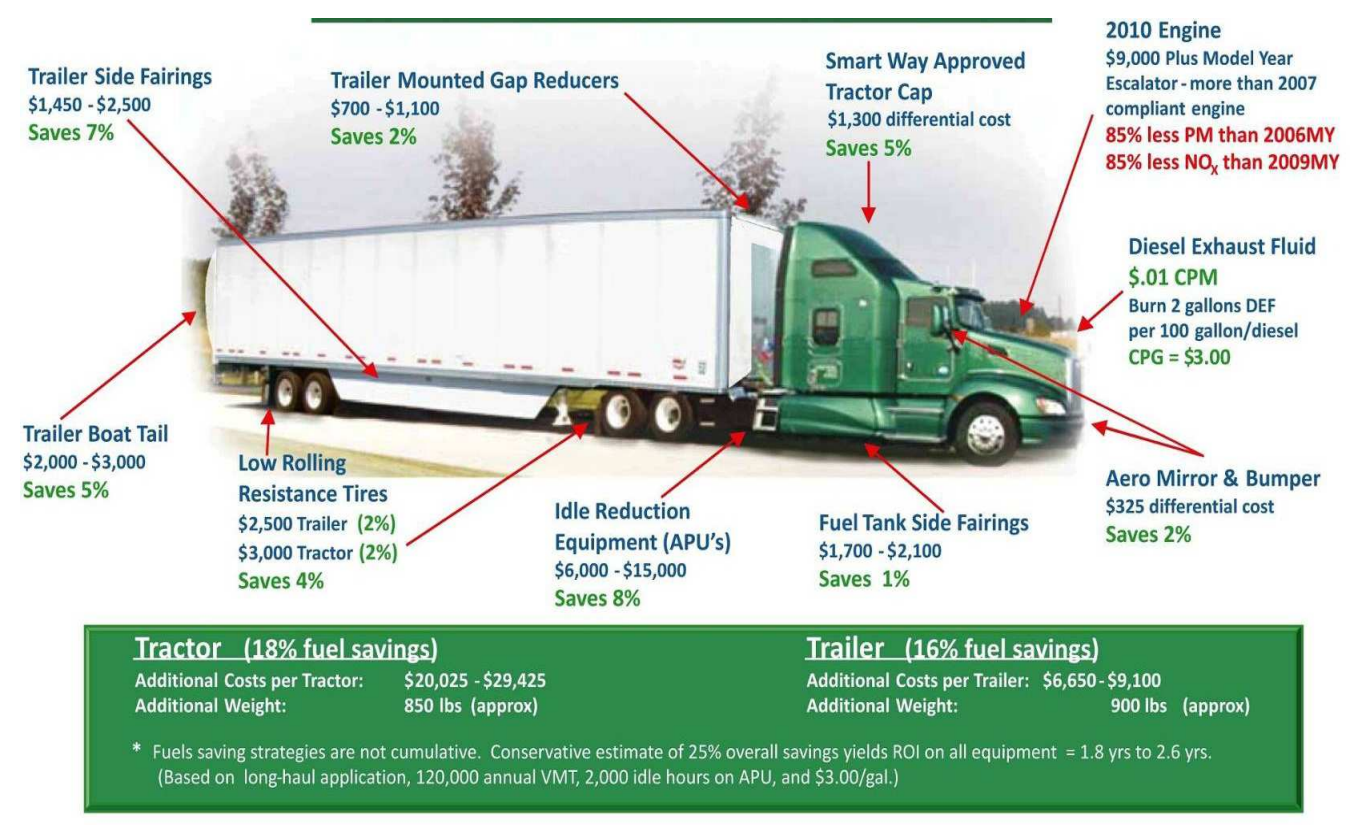

* Information Courtesy of Interstate Distributor Company: IDC Shippers Summit \& Green Freight Training Program 2010

Figura 6. Tecnologias certificadas nos EUA [8] 
A Tabela 3 apresenta o potencial de redução de consumo em relação às tecnologias embarcadas, segundo a United States Transport Research Board de 2010 [9].

Tabela 3 - Potencial de redução de consumo por tecnologia

\begin{tabular}{|l|c|}
\hline Tecnologia & Potencial Redução de Consumo (\%) \\
\hline Aerodinâmica & 3 a 15 \\
\hline Componentes Auxiliares & 1 a 2,5 \\
\hline Rolamento (pneus) & 4,5 a 9 \\
\hline Redução de Peso & 2 a 5 \\
\hline Redução de Marcha Lenta & 5 a 9 \\
\hline Tecnologias de Monitoramento & 8 a 15 \\
\hline
\end{tabular}

Baseando-se neste potencial e considerando a frota de estudo de 9.000 caminhões de transporte de carga rodando cerca de $54.000 \mathrm{~km}$ por ano cada um, pode-se sugerir a terceira alternativa:

Atuando apenas na aerodinâmica, considerando-se conservadoramente a redução de $3 \%$ no consumo de combustível e nos pneus, da mesma forma adotando-se 4,5\% de redução de consumo, pode-se obter uma economia anual de diesel da ordem de 13 milhões de litros, correspondendo aos 7,5\% dos $170 \mathrm{MM} 1$ consumidos anualmente por esta frota. Adicionalmente, evita-se potencialmente a emissão de cerca de 34 mil toneladas de $\mathrm{CO}_{2}$ por ano.

\section{FUTURO DA MOBILIDADE}

Existem diferentes visões em relação às tendências de introdução de novas tecnologias da mobilidade nas próximas décadas. Segundo a visão da Toyota [10], os veículos, no futuro, serão produzidos por "zonas de tecnologias" (elétricos, híbridos, plug-in e a célula de combustível), dependendo do tamanho e da aplicação (serviço e distância dos deslocamentos), conforme pode ser visto na Figura 7.

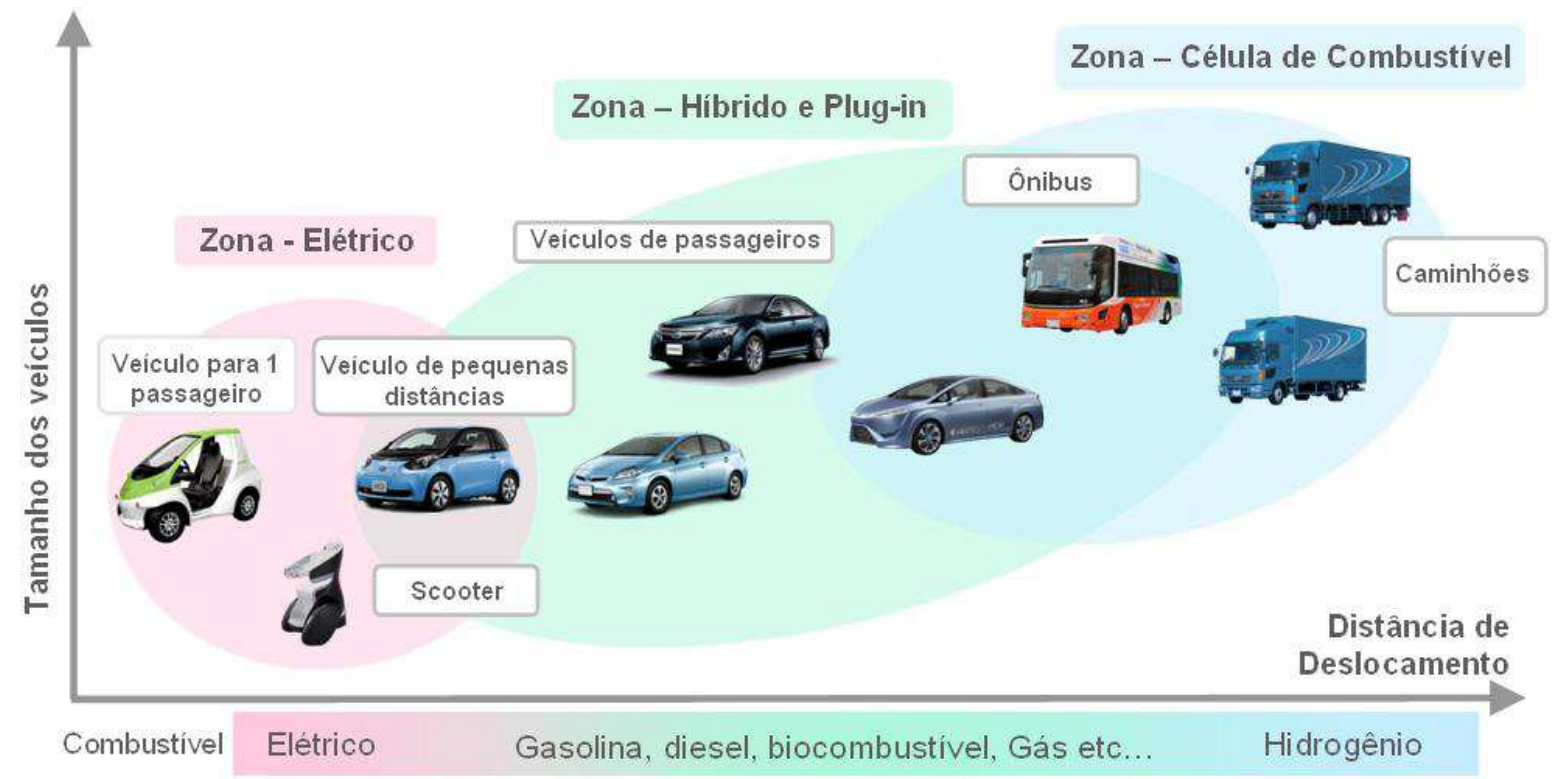

Figura 7. Visão Toyota - Zonas de Mobilidade [10]. 
Como pode ser observado, no futuro os veículos pesados de transporte de cargas poderão ser movidos à célula de combustível, utilizando hidrogênio como combustível.

Mas antes destas tecnologias tornarem-se técnica e economicamente viáveis, entende-se que alguns avanços tecnológicos não tão disruptivos poderiam ser empregados, por serem desenvolvimentos atuais de renomadas montadoras e sistemistas de veículos.

Como exemplo, pode-se ressaltar o sistema Híbrido Hidráulico desenvolvido pela fabricante MAN Latin America [11], onde a energia cinética é transformada em energia potencial hidráulica e armazenada em acumuladores para depois ser devolvida ao veículo em forma de movimento. Na Figura 8 pode-se verificar a economia de combustível em função da velocidade do veículo equipado com esta tecnologia.

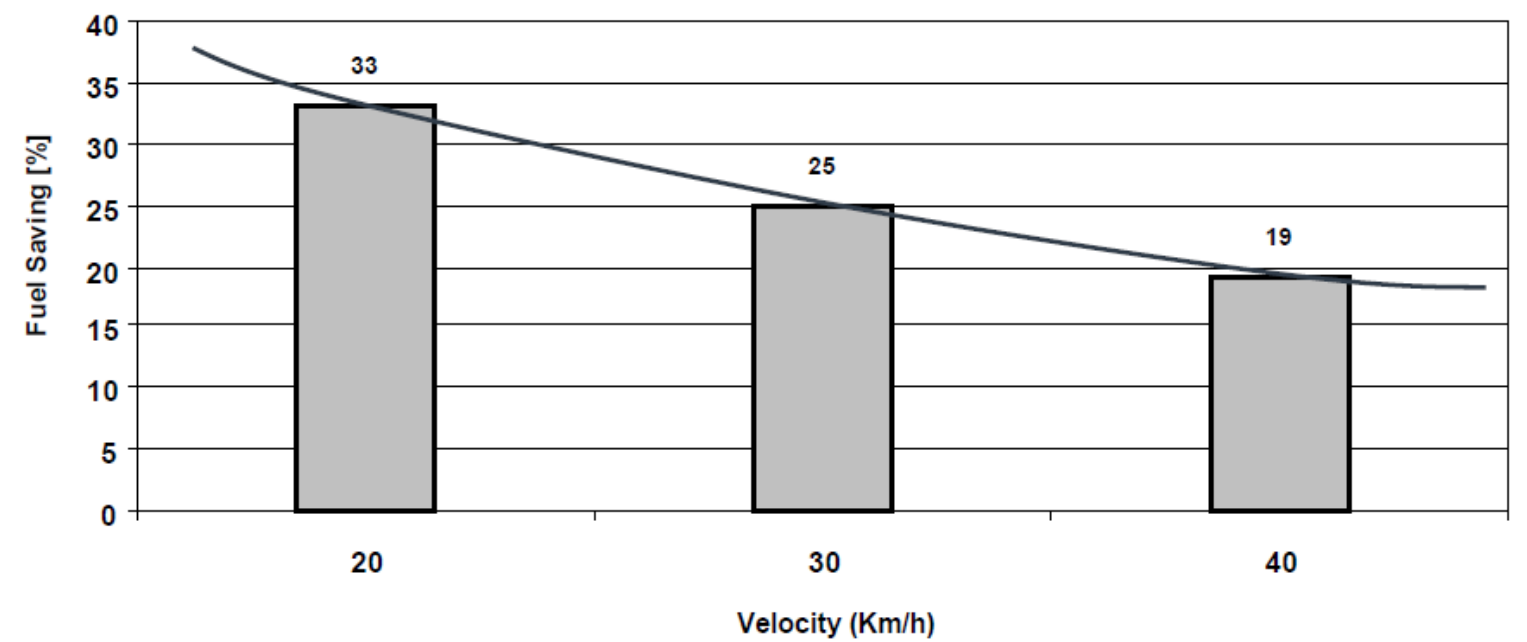

Figura 8. Economia de combustível com o sistema Híbrido Hidráulico [11]

Outro exemplo possível de ser implementado é o Sistema Dual-Fuel - Diesel-GNV desenvolvido pela Bosch [12], que apresenta o mesmo desempenho do uso apenas com o diesel, redução das emissões dos poluentes emitidos, principalmente do material particulado e com a excelente redução de cerca de $30 \%$ no custo dos combustíveis, pela substituição parcial do diesel pelo GNV.

Ambas as tecnologias apresentadas devem, ainda, ser exaustivamente testadas e, obviamente introduzem custos nas suas instalações, o que não faz parte do escopo deste trabalho técnico, mas permite sugerir a quarta alternativa para a frota em análise de 9.000 veículos pesados de transporte de carga rodando cerca de $54.000 \mathrm{~km}$ cada um, por ano:

3.1. Quarta alternativa: Avaliar novas formas de propulsão:

Adotando-se, por exemplo, a tecnologia do sistema híbrido hidráulico, potencialmente seria possível uma economia anual de diesel de aproximadamente 32 milhões de litros por ano, considerando-se conservadoramente uma redução de $19 \%$ do consumo anual de 170 MM 1 para toda a frota. Adicionalmente, evita-se a emissão de até 86 mil toneladas de $\mathrm{CO}_{2}$ por ano. 


\section{CONCLUSÕES}

Este trabalho apresenta, de forma quantitativa, o potencial ganho com a redução de consumo e de emissões de $\mathrm{CO}_{2}$ por ano de utilização de uma frota real de 1.000 veículos leves compactos, cada um rodando cerca de $20.000 \mathrm{~km} / \mathrm{ano}$, apenas selecionando os veículos através do PBEV:

- O melhor veículo em relação ao consumo combinado de gasolina na categoria compacto (A-categoria e A-geral) percorre $13,9 \mathrm{~km} / \mathrm{l}$ e o atualmente utilizado (Ccategoria e B-geral) apenas 11,2 km/l. Rodando cerca de $20.000 \mathrm{~km} / \mathrm{ano}$, o primeiro consome um total de 1439 1/ano de gasolina, enquanto o segundo 1786 $1 /$ ano.

- A diferença, portanto, entre estes veículos é de 347 litros de gasolina por ano, podendo totalizar uma economia de até 347.0001 de gasolina por ano de rodagem da frota, correspondendo a 19,3\% do consumo anual de 1,8 Milhões de litros.

- A respectiva diferença de emissão de $\mathrm{CO}_{2}$ fóssil entre eles seria de $460 \mathrm{~kg}$ por ano para cada veículo, com potencial redução de até 460 toneladas de $\mathrm{CO}_{2}$ fóssil por ano para toda a frota.

Em relação à frota de 9.000 veículos pesados de transporte de carga, alvo deste trabalho, apresentam-se três alternativas de aumento da eficiência energética com a respectiva redução de $\mathrm{CO}_{2}$ :

\section{- Acelerar a renovação da frota "pesada":}

Utilizando os valores de consumo do Inventário de Emissões, passando todos os caminhões da tecnologia P5 para a P7, os semipesados passariam do consumo médio de 228 para $219 \mathrm{~g} / \mathrm{kWh}$ e os pesados de 234 para $208 \mathrm{~g} / \mathrm{kWh}$, o que traria uma economia de diesel de cerca de 5 milhões de litros por ano, que correspondem a 3\% do consumo de toda a frota (170 MM 1). Complementando, evita-se a emissão de 13,3 mil toneladas de $\mathrm{CO}_{2}$ por ano.

\section{- Implementar tecnologias de componentes:}

Atuando apenas na aerodinâmica, considerando-se conservadoramente a redução de $3 \%$ e nos pneus, da mesma forma adotando-se 4,5\%, pode-se obter uma economia anual de diesel da ordem de 13 milhões de litros, correspondendo aos 7,5\% dos $170 \mathrm{MM} 1$ consumidos anualmente por esta frota. Adicionalmente, evita-se potencialmente a emissão de cerca de 34 mil toneladas de $\mathrm{CO}_{2}$ por ano.

\section{- Avaliar novas formas de propulsão:}

Adotando-se, por exemplo, a tecnologia do sistema híbrido hidráulico, potencialmente seria possível uma economia anual de diesel de aproximadamente 32 milhões de litros por ano, considerando-se conservadoramente uma redução de $19 \%$ do consumo anual de 170 MM 1 para toda a frota. Adicionalmente, evita-se a emissão de até 86 mil toneladas de $\mathrm{CO}_{2}$ por ano.

Cabe ressaltar que este trabalho não entrou no campo da viabilidade econômica das alternativas propostas, considerando apenas a viabilidade técnica delas, com os respectivos ganhos de $\mathrm{Eco}_{2}$ Eficiência para a frota selecionada. 


\section{REFERÊNCIAS}

[1] INMETRO, 2015, Tabelas de Consumo / Eficiência Enegética de Veículos Automotores Leves, Disponível em: http://www.inmetro.gov.br/consumidor/pbe/veiculos_leves_2015.pdf.

[2] CONPET, 2015, Programa Brasileiro de Etiquetagem - Consulta de Veículos Leves, Disponível em: http://pbeveicular.petrobras.com.br/TabelaConsumo.aspx.

[3] ABNT NBR 7024, 2010, Veículos rodoviários automotores leves - Medição do consumo de combustível - Método de ensaio, Associação Brasileira de Normas Técnicas, Rio de Janeiro, Brasil.

[4] ABNT NBR 10312, 2014, Veículos rodoviários automotores leves - Determinação da resistência ao deslocamento por desaceleração livre em pista de rolamento e simulação em dinamômetro.

[5] MDIC/INMETRO, 2008, Portaria 391, 04 de novembro de 2008.

[6] MMA, 2013, Inventário Nacional de Emissões Atmosféricas por Veículos Automotores Rodoviários 2013, Brasília, janeiro 2014

[7] NATIONAL ACADEMY OF SCIENCES, DOE Supertruck Program, 2010

[8] IDC, Shippres Summit \& Green Freight Training Program, 2010

[9] UNITED STATES TRANSPORT RESEARCH BOARD, 2010.

[10] TOYOTA DO BRASIL, Veículos Hibrido e Fuel Cell, Seminário de Propulsões Alternativas AEA, São Caetano do Sul, Apresentado em 29 de abril de 2015.

[11] MAN LATIN AMERICA, Ganhos Energéticos do Caminhão Híbrido, $1^{\circ}$ Seminário Internacional de Eficiência Energética, Brasília, Apresentação em 05 de junho de 2013.

[12] BOSCH, Sistema Diesel-Gás, Disponível em http://www.bosch.com.br/Imprensa/Releases/Detalhes.aspx?idRelease $=8608$ 